\title{
THE SOCIAL COSTS OF SMOKING IN AUSTRALIA
}

\section{David Collins}

Department of Economics

Macquarie University

Helen Lapsley

Centre for National Research on Disability and

Rehabilitation Medicine

University of Queensland

\section{BACKGROUND}

The implementation of effective policies that reduce the prevalence of smoking has substantial economic benefit for Australia. This article describes how methods for estimating the social costs of smoking were developed and how these methods have been applied to the Australian population and to measure the effect of interventions to reduce smoking prevalence in some states.

For many years, the major dispute between the tobacco industry and the public health community was over the issue of whether smoking caused morbidity and premature mortality, or whether there was simply a statistical association without a causal connection. In the face of the type of evidence comprehensively surveyed in several recent international and Australian meta-analyses, and particularly in the light of admissions about causality contained in now public internal tobacco industry documents, the industry has been forced to concede defeat on this front.

As a reaction, the industry has shifted the main thrust of its defence to economic arguments, asserting for example that:

- smokers make fully-informed, rational decisions to smoke, and so have decided that the benefits to them of smoking outweigh any costs that they may bear as a consequence of their tobacco consumption;

- any smoking-attributable costs that may be borne by the community are outweighed by community benefits, such as the pleasure that smokers enjoy and the tobacco tax revenue received by governments;

- the tobacco industry confers great benefits on the community, because it generates substantial employment in the manufacture and distribution of cigarettes.

These assertions may appear to be plausible and yet, when subject to the rigours of economic analysis, are usually shown to be false.

An important basis for economic discussion of the effect of smoking is information on its economic costs to the community as a whole. This information is required to demonstrate the size of the policy problem; without it, it is difficult to estimate the potential economic returns to public anti-smoking policies or to evaluate individual anti-smoking policies or programs.
For more than a decade, we have been engaged in research on the social costs in Australia of smoking as well as those for the use of alcohol and illicit drugs. The quality and coverage of these estimates have improved as the quality of the data has improved and the estimation methodology has been refined. This refinement has benefited from the international exchange of ideas with economists engaged in producing cost studies in other countries, culminating in the publication by the World Health Organization of international guidelines for estimating the costs of substance abuse. ${ }^{1}$ We have also benefited from developments in Australian epidemiological research, which represents a fundamental data requirement for this type of study.

Since 1991, we have produced for the National Drug Strategy a series of three monographs describing the social costs of drug abuse in Australia, disaggregating the costs by type of drug. These reports are:

- Estimating the economic costs of drug abuse, ${ }^{2}$ which was the first attempt in Australia to produce comprehensive estimates of the social costs of drug abuse, and one of the first world-wide. The social costs of drug abuse were estimated for the calendar year 1988. The research was based on epidemiological work undertaken at the University of Western Australia that quantified drug-attributable mortality and morbidity. ${ }^{3}$

- The social costs of drug abuse in Australia in 1988 and 1992, ${ }^{4}$ which presented social cost estimates for 1992 on the basis of a new meta-analysis from the University of Western Australia, ${ }^{5}$ newly available casemix health care cost data and other improved data. The report also presented revised estimates for 1988 on a basis consistent with the new 1992 estimates. Thus it was possible to gain an indication of how the social costs of drug abuse (including tobacco) were changing over time.

- Counting the cost: estimates of the social costs of drug abuse in Australia in 1998-99, ${ }^{6}$ which presented new estimates for the financial year 1998-99 on the basis of a revised meta-analysis produced by the Australian Institute of Health and Welfare, ${ }^{7}$ and improved data from other areas. The range of smoking-attributable costs estimated was extended to include involuntary smoking, workplace absenteeism, pharmaceuticals, and fires. Because of the increased range of the estimates, the 1998-99 figures are not directly comparable to earlier estimates.

\section{INTERPRETING SOCIAL COST ESTIMATES}

The smoking costs estimated in these studies are social costs (often called external costs), as opposed to private costs. For costs to be defined as private costs two important conditions must be simultaneously satisfied: 
- smokers must themselves bear the full costs of smoking that they generate, including most importantly health and productivity costs;

- smokers must be fully informed about the effects and costs of their smoking, and they must have made rational decisions to smoke in the light of the full information available to them.

Since it is most unlikely in the Australian context that these two conditions are simultaneously satisfied, virtually all the costs imposed by smokers, even on themselves, can be considered to be social costs.

These types of studies concentrate on estimation of social, rather than private, costs and benefits because it is the social measures that provide the basis for public policy. If individual decisions to smoke were made rationally on a fully informed basis, and if the individual smokers themselves bore all the costs that their smoking caused, then their decisions could be assumed to accord with their own self-interest with no one else being affected. In these unlikely circumstances, government intervention could not improve the lot of the smokers or of anyone else. However, if these conditions are not satisfied, that is, if social costs exist, government intervention has the potential to improve the welfare of the community as a whole.

\section{METHOD}

Two broad techniques are available to estimate the social costs of drug abuse: the 'human capital' approach and the 'demographic' approach. The key difference between the two is the way in which the costs of premature mortality are treated. In the human capital approach, the lost value of a deceased worker's production is represented by the discounted present value of the future time stream of lost production. The demographic approach uses a comparison of the actual population with the hypothetical alternative population that would have existed had there been no drug abuse. Thus, the human capital approach produces an estimate of the present and future costs due to drugrelated mortality in the current year, while the demographic approach estimates the present costs of drug-related mortality in past and present years. ${ }^{1}$

Our social cost estimates are based on the demographic method which, it can be argued, provides results that are easier to understand than those estimated by the human capital method. The current size and structure (disaggregated by age and sex) of the Australian population are compared with those that would have existed in a theoretically-counterfactual situation in which there had been no smoking in the previous 40 years. It then becomes possible to compare the two populations for such characteristics as labour force size and structure, and the demand for health care, and so to estimate the social costs borne in the year under review as a result of past and present smoking. This type of analysis requires not only epidemiological information but also demographic analysis, and is most efficiently conducted by teams that include a range of skills rather than by economists working alone. It cannot be effectively conducted without substantial economic input, although regrettably there are various examples in the literature where this has been attempted. The economic issues in this type of research should not be underestimated, as is clearly demonstrated in the International Guidelines. ${ }^{1}$

We have extended the range of these types of studies to incorporate estimates of:

- Avoidable costs-the proportion of aggregate social costs that might be prevented over time by appropriate anti-smoking policies;

- Budgetary costs-the effect of smoking on government budgets rather than on the community as a whole;

- Incidence of social costs-the disaggregation of the costs between various community sectors (individuals, business and government).

\section{RESULTS}

Table 1 summarises the most recent estimates of the social costs of smoking in Australia for the financial year 1998-99.

Some further results were:

- a high proportion of the health effects of involuntary smoking was borne by the young or the unborn;

- of the total costs estimated for all forms of drug abuse (excluding abuse of pharmaceuticals) in Australia in 1998-99, smoking is by far the largest contributor, accounting for 61 per cent of the total. Alcohol accounted for 22 per cent and illicit drugs accounted for 17 per cent;

- the avoidable costs of smoking represented 45 per cent of total costs;

\section{TABLE 1}

ESTIMATE OF THE SOCIAL COST OF SMOKING FOR THE FINANCIAL YEAR, AUSTRALIA, 1998-99

\begin{tabular}{|c|c|c|}
\hline & \$ million \$ & \$ million \\
\hline \multicolumn{3}{|l|}{ Tangible costs } \\
\hline Lost production (net) & 5,064 & \\
\hline Health care & 1,095 & \\
\hline Fires * & 26 & \\
\hline $\begin{array}{l}\text { Resources used in } \\
\text { cigarette production }\end{array}$ & 1,402 & \\
\hline $\begin{array}{l}\text { Total tangible costs } \\
\text { Intangible costs }\end{array}$ & & 7,587 \\
\hline Value of loss of life & 13,476 & \\
\hline Total intangible costs & & 13,476 \\
\hline Total costs & & 21,063 \\
\hline \multicolumn{3}{|c|}{$\begin{array}{l}\text { * Not included under lost production or health care. } \\
\text { Source: Collins and Lapsley, } 2002{ }^{6}\end{array}$} \\
\hline
\end{tabular}


- of the total tangible costs of smoking 59 per cent were borne by individuals, 30 per cent were borne by business, and only 11 per cent were borne by governments. By their nature, all intangible costs (pain and suffering and loss of life) are borne by individuals:

- smoking increased federal and state government outlays by $\$ 885$ million but increased tax revenues by $\$ 3,647$ million (taking into account some revenue losses). Thus, governments gain a substantial economic benefit from smoking while the community as a whole bears very high economic costs greatly exceeding revenue from tobacco taxes.

\section{CONCLUSION}

The authors are currently engaged in a research study for the NSW Department of Health to estimate the social costs of smoking in NSW, and the social benefits of reducing the prevalence of smoking in NSW. We have also undertaken studies for two other states of the benefits of anti-smoking policies. These studies are:

- The social costs of tobacco in Victoria and the social benefits of Quit Victoria, ${ }^{8}$ an estimate of the benefits of expenditures on Quit Victoria, which indicated that they had yielded a very high social rate of return in Victoria;

- The social costs of tobacco in Western Australia and the social benefits of reducing Western Australian smoking prevalence, ${ }^{9}$ which estimated that the social benefits of achieving the objective of the Western Australian Target 15 campaign to reduce smoking prevalence to 15 per cent would be greater by a very considerable margin than the resources currently expended on anti-smoking programs in that State.

These results, together with our calculations of avoidable smoking costs, show that the implementation of effective policies to reduce smoking can have great economic benefits for Australia.
The publication Counting the cost: Estimates of the social costs of drug abuse in Australia in 1998-99 is available online from www.health.gov.au/pubhlth/ publicat/document/mono49.pdf.

\section{REFERENCES}

1. Single E, Collins D, Easton B, Harwood H, Lapsley H, Kopp $\mathrm{P}$, and Wilson E. International Guidelines for Estimating the Costs of Substance Abuse: Second edition. Geneva: World Health Organization, 2003.

2. Collins DJ and Lapsley HM. Estimating the economic costs of drug abuse. National Campaign Against Drug Abuse: Monograph Series No. 15, 1991.

3. Holman CDJ, Armstrong BK et al. The Quantification of Drug Caused Mortality in Australia 1989. Canberra: Commonwealth Department of Community Services and Health, 1990.

4. Collins DJ and Lapsley HM. The social costs of drug abuse in Australia in 1988 and 1992. National Drug Strategy Monograph Series No. 30, 1996.

5. English DR, Holman CDJ et al. The quantification of drug caused morbidity and mortality in Australia: 1995 edition. Canberra: Commonwealth Department of Human Services and Health, 1995.

6. Collins DJ and Lapsley HM. Counting the cost: Estimates of the social costs of drug abuse in Australia in 1998-99, National Drug Strategy Monograph Series No. 49, 2002. Available online at www.health.gov.au/pubhlth/publicat/ document/mono49.pdf.

7. Ridolfo B and Stevenson C. The quantification of drugcaused mortality and morbidity in Australia, 1998. Australian Institute of Health and Welfare, Drug Statistics Series no. 7, 2001.

8. Collins DJ and Lapsley HM. The Social Costs of Tobacco in Victoria and the Social Benefits of Quit Victoria. Melbourne: Victorian Smoking and Health Program, 1999.

9. Collins DJ and Lapsley HM. The Social Costs of Tobacco in Western Australia and the Social Benefits of Reducing Western Australian Smoking Prevalence. Perth: Cancer Foundation of Western Australia, Monograph Series no. 1, 2001. 